\title{
Rock Magnetic Characterization of Fine Particles from Car Engines, Brake Pads and Tobacco: An Environmental Pilot Study on Oahu, Hawaii, USA
}

\author{
Emilio Herrero-Bervera* (1), Karl Gerstnecker, Vanessza Lopez, Brian Swilley \\ Magnetic Materials, Paleomagnetic and Petrofabric Laboratory, Hawaii Institute of Geophysics and Planetology (SOEST), \\ University of Hawaii at Manoa, Honolulu, HI, USA \\ Email: ^herrero@soest.hawaii.edu
}

How to cite this paper: Herrero-Bervera, E., Gerstnecker, K., Lopez, V., \& Swilley, B. (2020). Rock Magnetic Characterization of Fine Particles from Car Engines, Brake Pads and Tobacco: An Environmental Pilot Study on Oahu, Hawaii, USA. Journal of Geoscience and Environment Protection, 8, 130-139.

https://doi.org/10.4236/gep.2020.86010

Received: January 1, 2020

Accepted: June 27, 2020

Published: June 30, 2020

Copyright $\odot 2020$ by author(s) and Scientific Research Publishing Inc. This work is licensed under the Creative Commons Attribution International License (CC BY 4.0).

http://creativecommons.org/licenses/by/4.0/

\section{(c) (i) Open Access}

\begin{abstract}
Today, it is well known that small airborne particles are very harmful to human health. For the first time in Hawaii we have conducted an environmental pilot study of fine magnetic particles on the island of Oahu, Hawaii, of particulate matter $(\mathrm{PM}) \mathrm{PM}=60, \mathrm{PM}=10$, and $\mathrm{PM}=2.5$. In order to do a rock magnetic characterization we have performed low field susceptibility vs. temperature $[\mathrm{k}-\mathrm{T}]$ experiments to determine the Curie points of small particles collected from exhaust pipes, as well as from brake pads of four different types of car engines using gasoline octane ratings of 87,89 , and 92 . The Curie point determinations are very well defined and range from $292^{\circ} \mathrm{C}$ through $393^{\circ} \mathrm{C}$ and up to $660^{\circ} \mathrm{C}$. In addition, we have conducted magnetic granulometry experiments on raw tobacco, burnt tobacco ashes, as well as on automotive engine exhaust, and brake pads in question. The results of the experiments show ferro and ferrimagnetic hysteresis loops with magnetic grain sizes ranging from superparamagnetic-multidomain [SP-MD], multidomain $[\mathrm{MD}$ ] and pseudo-single domain [PSD] shown on the modified Day et al., diagram of Dunlop (2002). Thus far, the results we have obtained from this pilot study are in agreement with other studies conducted from cigarette ashes from Bulgaria. Our results could be correlated to the traffic-related PM in Rome, Italy where the SP fraction mainly occurs as coating of MD particles originated by localized stress in the oxidized outer shell surrounding the un-oxidized core of magnetite-like grains. All these magnetic particles have been reported to be very harmful to our human bodies (i.e. brain, lungs, heart, liver etc.).
\end{abstract}




\section{Keywords}

Particulate Matter, Magnetic Minerals, Magnetic Susceptibility, Curie Points, Magnetic Grain Sizes, Cigarette Ashes, Tobacco, Gasoline, Brake Pads

\section{Introduction}

Airborne pollution is an ever-increasing issue and cause for numerous human health conditions such as respiratory and cardiovascular ailments. Especially prominent in our urban areas, airborne pollution consists of a wide array of particulate sizes and compositions. An often overlooked aspect of our daily lives is our contribution to airborne pollution.

The simple act of driving one's vehicle creates a plethora of airborne pollutants and furthermore these pollutants are often magnetized. Our vehicle does not make gasoline simply vanish. Our fuel is stored in a metal tank, sent through a mechanical pump to your engine where it is combusted in a hot mass of various different types of moving metal and then as a gaseous mixture, it is sent out of the engine through a hot pipe and into the air. Our brake pads and our tires do not simply disappear either. These wearable items also contain metals that are slowly ground down through normal use contributing to airborne pollution. Even the act of smoking a cigarette can contribute to magnetic particulates in the air.

Medical science is just beginning to understand the impact that ingested or inhaled magnetic pollution can have on the human body. A recent study showed that iron oxide $\left(\mathrm{Fe}_{3} \mathrm{O}_{4}\right)$ magnetite nanoparticles in the human brain may be the cause of Alzheimer's disease (Curtis et al., 2006; Plascencia-Villa et al., 2016).

The aim of this study is to utilize rock magnetic measurement techniques to characterize the airborne pollution created by normal automotive use as well as by cigarettes. The exhaust particulate built up in different vehicles tailpipes as well as in vehicles utilizing different octane gas will be tested as well as brake pad dust and cigarette tobacco and its ashes.

Through the environmental study and characterization of these sources of airborne pollution the resultant information may provide the medical community with better knowledge of just what exactly we as human beings face as airborne pollution. The aim of this study is to investigate the magnetic properties of traffic-produced airborne particulate matter (PM) and by raw tobacco and burnt ashes of cigarettes (e.g. Jordanova et al., 2006; Sagnotti \& Winkler, 2012), for the first time in the city Honolulu, Hawaii, USA.

\section{Sampling Methods and Materials}

After locating vehicles that were consistently fueled with the corresponding octane types (i.e. 87, 89, 92) an exhaust particulate sample was obtained from the inside of the tail pipe by swabbing with toilet paper until black. Brake pad dust was collected in a similar manner from around the brake caliper and adjacent 
wheel area. In addition, we have also recovered cigarette tobacco as well as ashes from a smoked cigarette in order to analyze the possible magnetic properties of such materials.

\section{Rock Magnetic Experiments}

\section{Magnetic susceptibility and mineralogy}

Magnetic properties were analyzed to identify the magnetic carriers of the natural remanent magnetization (NRM) and to investigate the origin of the NRM. Studies of magnetic mineralogy were performed first using 10 specimens of very small pieces of fragments of brake pads, particles of fumes in the exhaust tail pipes of vehicles as well as raw tobacco and burnt ashes of cigarettes (Sagnotti \& Winkler, 2012; Jordanova et al., 2006). The first experiment was to determine the magnetic susceptibility $\chi\left(\times 10^{8} \mathrm{~m}^{3} / \mathrm{kg}\right)$ of the ten specimens in question (see Table 1$)$. The values obtained range from very low values of 0.4 up to $\sim 192 \times 10^{8} \mathrm{~m}^{3} / \mathrm{kg}$.

Low-field susceptibility versus temperature $(k-T)$ experiments was conducted in air using a Multi-Function Kappabridge MFK-1 with a CS-3 attachment in order to determine the Curie temperature of the samples. Nine specimens were progressively heated from room temperature up to $700^{\circ} \mathrm{C}$ and subsequently cooled down using a CS3 apparatus (Hrouda, 1994; Hrouda et al., 1997) located at the SOEST-HIGP Magnetic Materials Laboratory. Several typical diagrams of susceptibility versus temperature (k-T) are shown in Figure 1. The curves have very dissimilar heating and cooling patterns. All of them show the presence of the Curie temperatures of pure magnetite as well as other magnetic mineral phases. We have found that ALL the specimens studied had reversible and irreversible heating and cooling results, with single inflection points, indicating $\mathrm{Cu}$ rie temperatures between low (i.e. $250^{\circ} \mathrm{C}$ ) and very high (i.e. $675^{\circ} \mathrm{C}$ ) temperatures (see Table 1). We have interpreted these data to indicate the presence of low-Ti magnetite, pure magnetite as well as hematite as the primary magnetic minerals in these samples (see Figure 1) as shown by the inflection points of the Curie point diagrams.

\section{Magnetic granulometry from hysteresis experiments}

Magnetic hysteresis measurements were performed on very small particles sampled from vehicles (i.e. brake pads, gasoline remains on the exhaust tail pipes), cigarettes and their ashes (i.e. a few milligrams) in order to determine their hysteresis properties and eventually their magnetic grain sizes. To achieve such tasks we used a variable field translation balance (VFTB) up to $1.2 \mathrm{~T}$. Saturation remanent magnetization $(\mathrm{Mr})$, saturation magnetization $(\mathrm{Ms})$, and coercive force $(\mathrm{Hc})$ were calculated after removing the paramagnetic contribution. We have determined the hysteresis loops and the back-field demagnetization curve of the saturation isothermal remanent magnetization (SIRM). The variable field translation balance (VFTB) instrument has a measuring range of $10^{-8}-10^{-2}$ $\mathrm{Am}^{2}$. The coercivity of remanence (Hcr) suggests that the Isothermal Remanent Magnetization (IRM) is carried by low-coercivity grains (see Figure 2), which is 

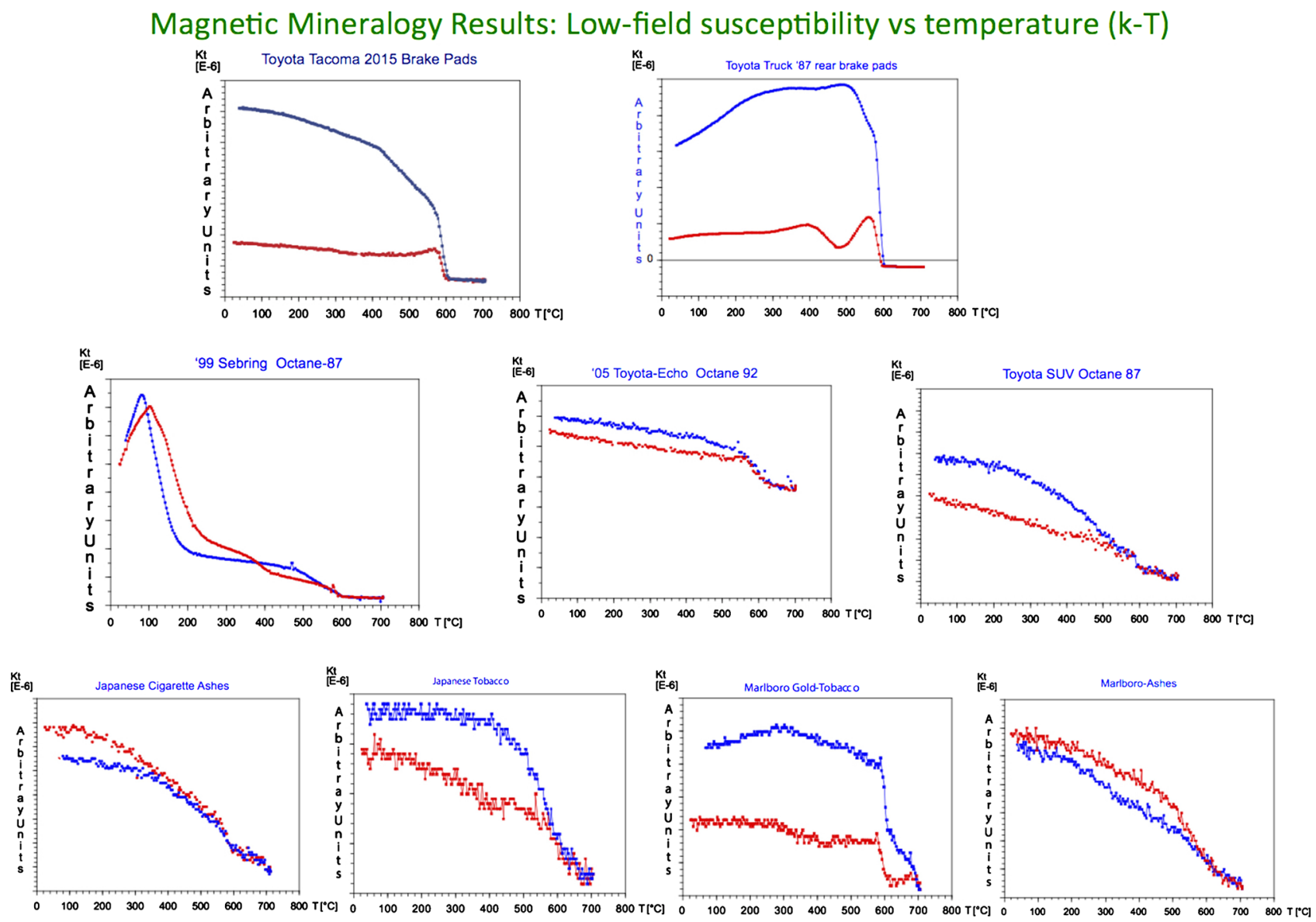

Figure 1. Results of nine low-field magnetic susceptibility versus temperature (k-T) Curie point curves obtained from small particles of brake pads, gasoline fuels (i.e. octane 87, 89 and 92, tobacco cigarettes and burnt tobacco ashes). Notice the diverse reversibility and irreversibility of the specimens tested as well as the variety of Curie point determinations.

Table 1. Magnetic characteristics of the studied gasolines, brake pads, tobacco and burnt ashes data. Hcr remanence coercivity field, Hc coercivity field, Ms saturation magnetization, Mrs/Ms ratio of remanence saturation relative to saturation magnetization, $\mathrm{Hcr} / \mathrm{Hc}$ ratio of remanence coercivity field to field coercivity, Magnetic domains, SD single domain, PSD pseudosingle domain, MD multidomain; $(\chi)$ bulk magnetic susceptibility $\left(10^{-6} \mathrm{~m}^{3} / \mathrm{kg}\right)$, Curie point determinations in degree centigrades.

\begin{tabular}{|c|c|c|c|c|c|c|c|c|c|}
\hline Samples. & Hcr & $\mathrm{Hc}$ & Mrs & Ms & $\mathrm{Mrs} / \mathrm{Ms}$ & $\mathrm{Hcr} / \mathrm{Hc}$ & $\begin{array}{c}\text { Magnetic } \\
\text { Domain }\end{array}$ & $\begin{array}{c}\text { Magnetic } \\
\text { susceptibility } \\
\text { E-06 }\end{array}$ & Curie points \\
\hline Sebring'99 & 19.65 & 6.66 & 0.0025 & 0.018 & 0.13743 & 2.95 & PSD & 81.8 & $\mathrm{~T} 1=220, \mathrm{~T} 2=410, \mathrm{~T} 3=3989$ \\
\hline Karl brake pad & 42.77 & 9.2 & 0.019 & 0.15 & 0.128 & 6.65 & PSD & 0.4 & $\mathrm{~T} 1=342, \mathrm{~T} 2=398$ \\
\hline Toyota Truck 87 front brakes & 47.0757 & 4.13868 & 0.005644 & 0.069 & 0.08 & 10.1665 & PSD & 768 & $\mathrm{~T} 1=299, \mathrm{~T} 2=465.6, \mathrm{~T} 3=598$ \\
\hline Toyota Truck 87 rear brakes & 47.0757 & 8.5 & 0.0073 & 0.069 & 0.106 & 5.54 & PSD & 19.2 & $\begin{array}{c}\mathrm{T} 1=295.3, \mathrm{~T} 2=482.6, \mathrm{~T} 3= \\
596.0\end{array}$ \\
\hline Toyota SUV & 8.72219 & 2.93 & 0.00106 & 0.00105 & 0.1004 & 2.97 & SD-MD & 9 & $\mathrm{~T} 1=384, \mathrm{~T} 2=500, \mathrm{~T} 3=593$ \\
\hline Toyota echo & 5.52155 & 1.41943 & 6.26 & 0.0001 & 0.0616 & 3.8899 & SD-MD & 9 & $\mathrm{~T} 1=396, \mathrm{~T} 2=524, \mathrm{~T} 3=626$ \\
\hline Japanese ashes & 26.65 & 8.71 & 0.0037 & 0.0017 & 0.219 & 3.06 & SD-MD & 7.3 & $\mathrm{~T} 1=572$ \\
\hline Japanese tobacco & 1.1722 & 1.68072 & 4.91 & 8.6632 & 0.0567 & 0.697 & PSD & 191.07 & $\mathrm{~T} 1=374, \mathrm{~T} 2=601.6$ \\
\hline Marlboro gold tobacco & 7.97 & 1.59 & 5.37 & 9.32 & 0.057 & 5.009 & PSD & 190.68 & $\mathrm{~T} 1=328, \mathrm{~T} 2=603$ \\
\hline Marlboro gold ahes & 22.49 & 1.82471 & 5.67 & 0.00078 & 0.07 & 12.32 & PSD & 188.26 & $\mathrm{~T} 1=531, \mathrm{~T} 2=602$ \\
\hline
\end{tabular}



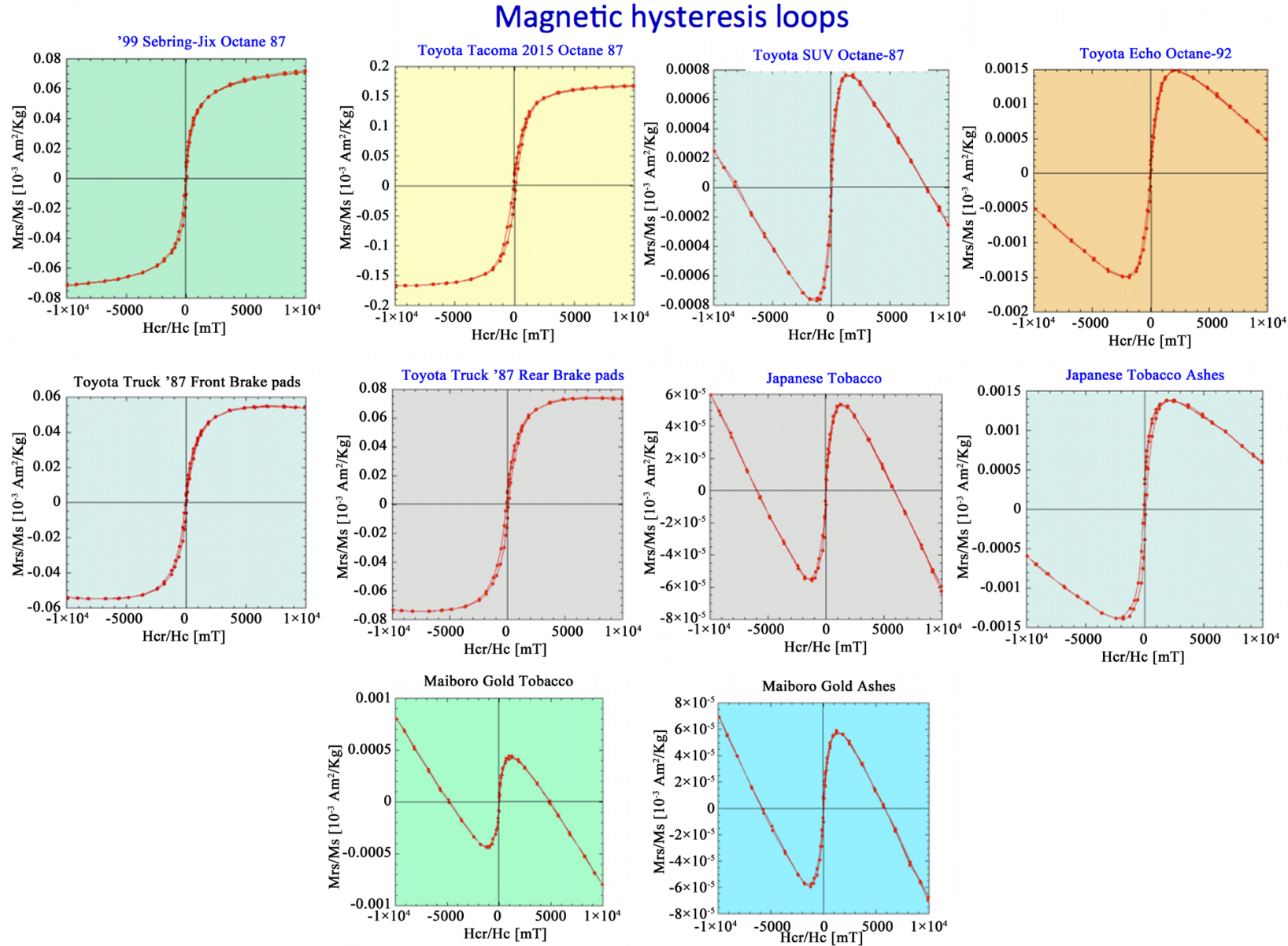

Figure 2. Results of the hysteresis loops experiments performed on ten samples obtained from small particles of brake pads, gasoline fuels (i.e. octane 87, 89 and 92), tobacco cigarettes and burnt tobacco ashes. The values obtained show their diverse ratios of the Mrs/Ms and $\mathrm{Hcr} / \mathrm{Hc}$ parameters. Notice the very small coercivities of all the hysteresis curves.

case for the ten specimens shown in Figure 2 (Tauxe et al., 1996). The ratios of hysteresis parameters were plotted in Figure 3 and Table 1 as a Day diagram (Day et al., 1977) following modifications by Dunlop (Dunlop, 2002) for type curves and regions that have been defined for pure magnetite.

Most grain sizes are scattered within the pseudo-single domain range (PSD) for the nine specimens under question (Tauxe et al., 1996). If we do not consider the influence of grain sizes, it is interesting to associate this distribution with the magnetic phases that are present in the sample. The hysteresis parameters have been initially defined from synthetic crystals of magnetite (Dunlop \& Özdemir, 1997). However we must keep in mind that we are dealing with samples that contain magnetic grains associated with different mineralogical phases. We wonder whether the characteristic values that separate the grain size domains for pure magnetite are fully appropriate in the presence of several mineralogical components with overlapping coercivity spectra and magnetizations (see Figure $3(b)$ ). This would probably explain why most studies deal with samples that are actually found within the pseudo-single domain range (e.g. Herrero-Bervera \& Valet, 2009; Tauxe et al., 1996). 


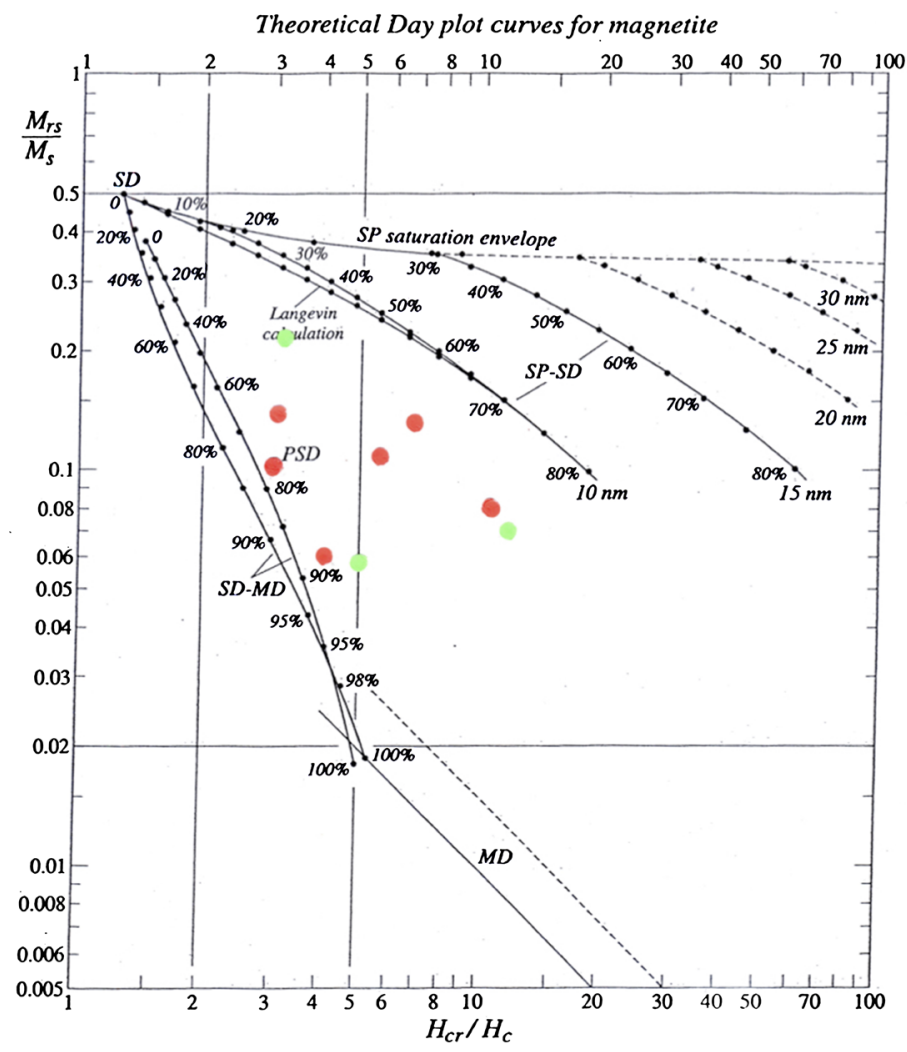

(a)

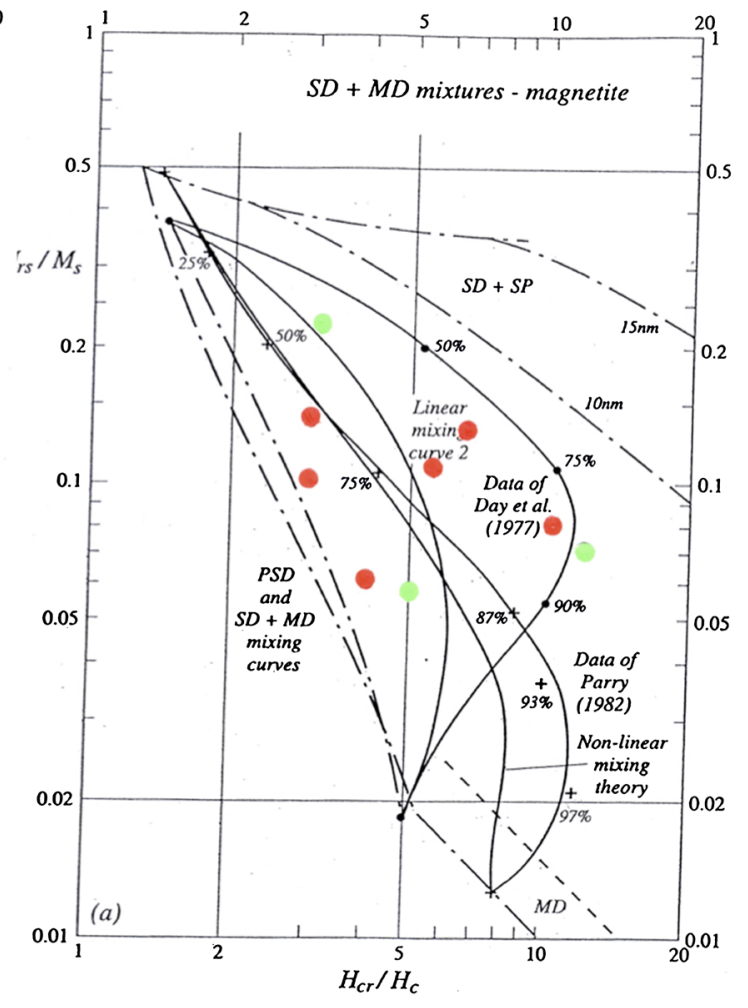

(b)

Figure 3. Theoretical Day plot curves calculated for (a) magnetite using the equations developed by Dunlop (2002) (Detailed explanations of individual curves are given in (Dunlop, 2002); (b) for SD +MD mixtures of magnetite. Numbers along curves are volume fractions of the soft component (SP or MD) in mixtures with SD grains published. The light green solid circles denote tobacco and also burnt ashes. The red solid circles denote brake pads and gasoline fuel small particles. $\mathrm{Y}$ axis for $10^{-3} \mathrm{Am}^{2} / \mathrm{Kg}$ and for the $\mathrm{X}$ axis use $\mathrm{mT}$.

\section{Discussion}

One of the objectives of this very rudimentary, elementary and simple magnetic experiment(s) is to test the hypothesis that in the city of Honolulu, Hawaii there are traffic-related particulate matter (PM), see Figure 4, as well as cigarette tobacco and burnt ashes (Jordanova et al., 2006) that pose a real threat to the health of the inhabitants of the city.

As it has been published in the recent past, airborne particulate matter is composed of a mixture of a variety of chemical and physical characteristics that harm the respiratory, cardiovascular, immunological, hematological, neurological and reproductive/developmental systems (e.g. Plascencia-Villa et al., 2016; Sagnotti \& Winkler, 2012; Thompson \& Oldfield, 1986) (Figure 5 and Figure 6).

As commented and published by (Curtis et al., 2006) magnetic susceptibility $(\chi)$ is a property of matter, that reflects substantially the concentration of the different iron-containing minerals, mostly iron oxides and sulfides in natural systems (WHO, 2006), assuming that the mineralogy does not vary. The other magnetic properties studied here such as the Curie point determinations and the hysteresis loops are also results that in a very initial phase, 


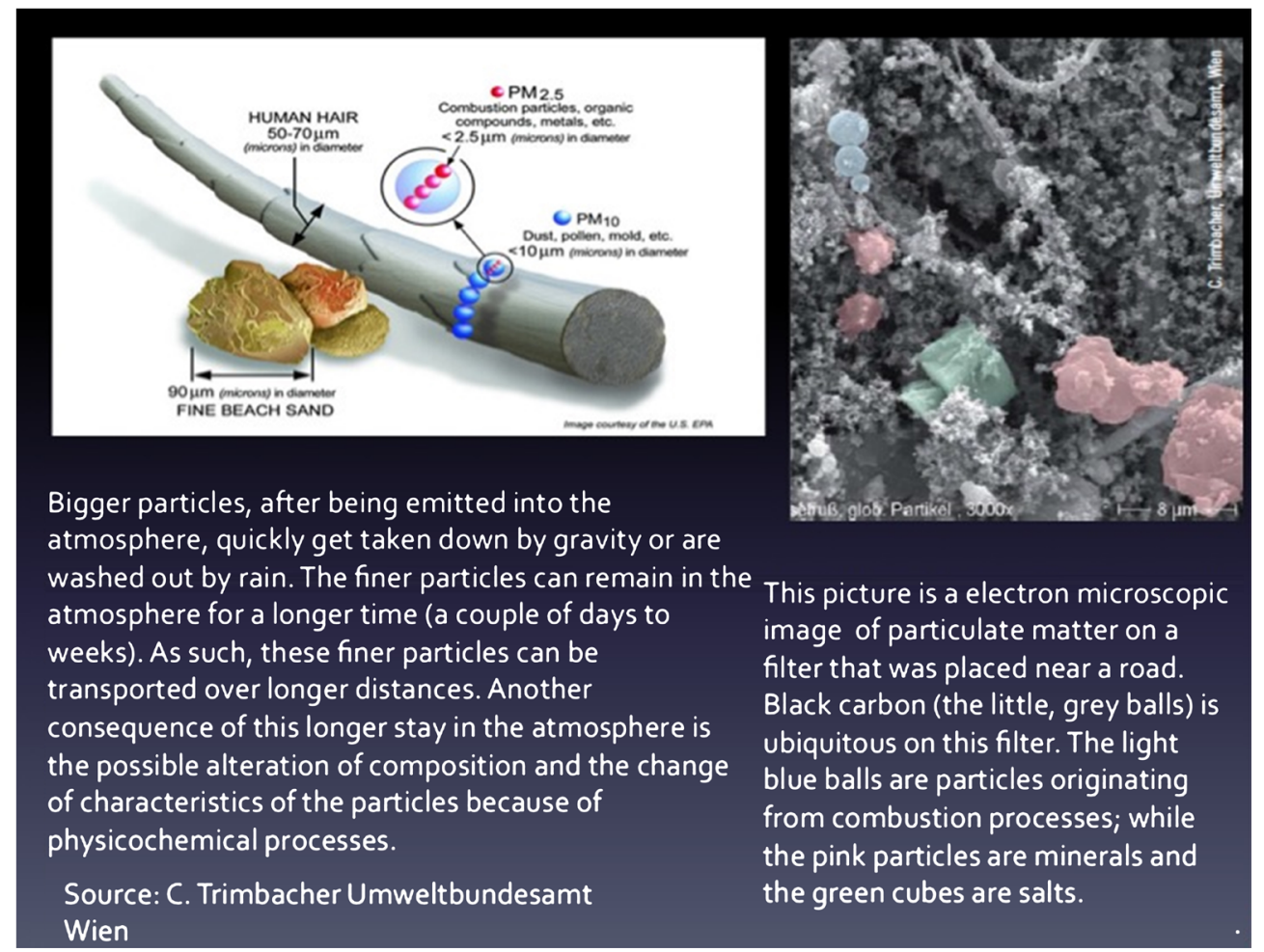

Figure 4. The atmosphere, in addition to gaseous pollulants is characterized by additional particles either in suspension, fluid or in solid state that have different compositions and sizes that are also called aerosols. Sometimes those particles are classified and called "floating dust" but in reality they are known as particulate matter (PM). The figure on the left side depicts the comparison with the thickness of a human hair (i.e. $50-70 \mu \mathrm{m}$ ), and $90 \mu \mathrm{m}$ of fine beach sand and $\mathrm{PM}_{2.5}$ (i.e. $<2.5 \mu \mathrm{m}$ ) and $\mathrm{PM}_{10}$ (i.e. $10 \mu \mathrm{m}$ ). The figure on the right hand side depicts light blue ball particles from combustion processes; the pink particles are minerals, and the green cubes salts. Image courtesy of the US EPA. Figure taken from C. Trimbacher Umweltbundesamt Wien.

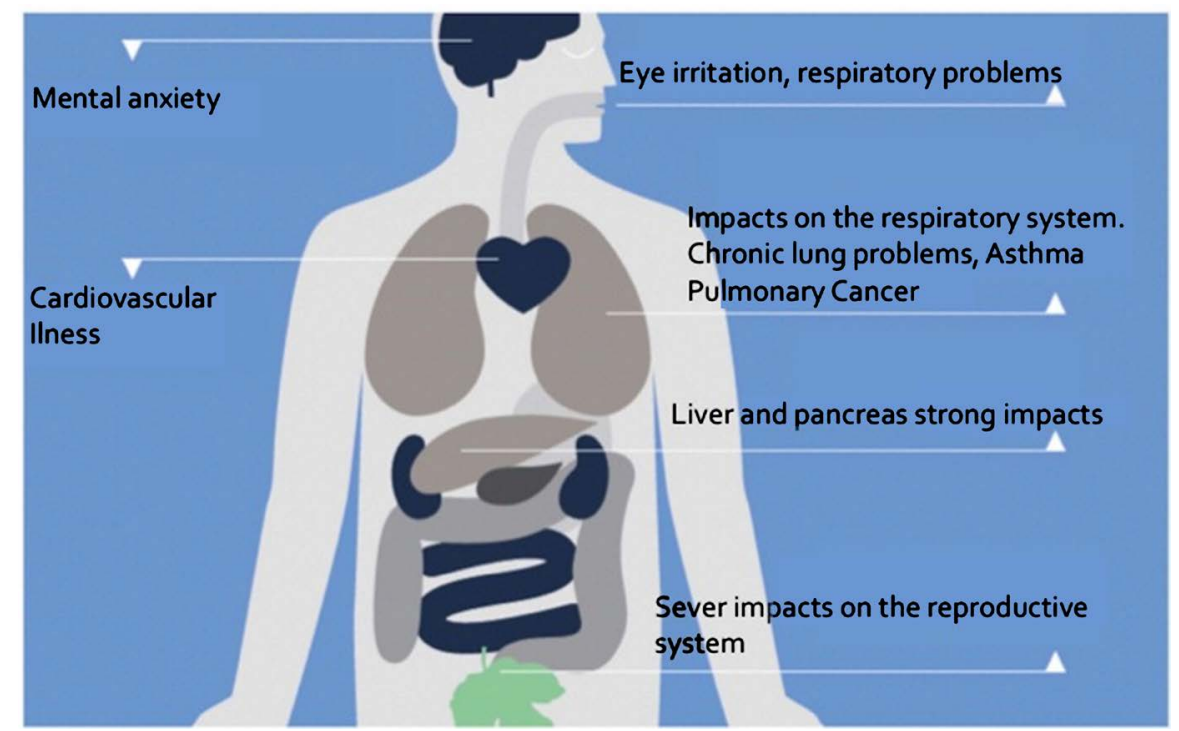

Figure 5. Modified diagram showing the possible illnesses caused by fine particles in the human body. The original figure was kindly provided by Professor Pierre Camps, Montpellier, France. 


\section{Origins of Fine Particles}

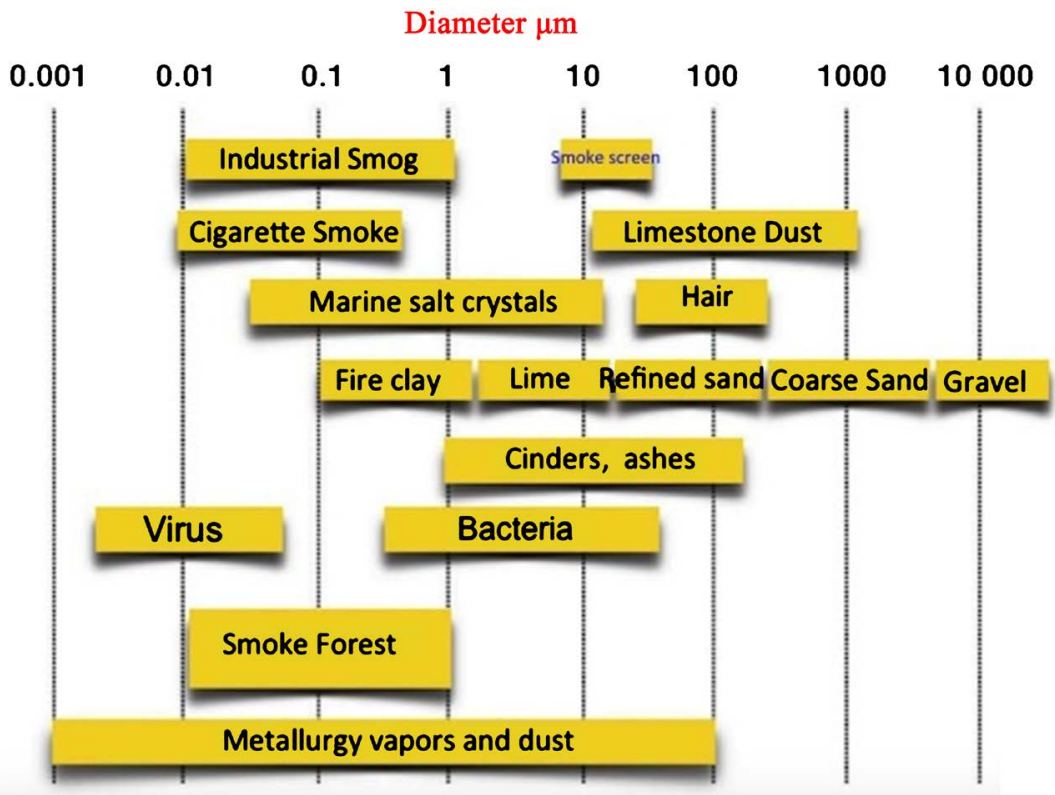

Figure 6. Modified diagram showing the origins of fine particles affecting humans. The diagram classifies the diamter in micro-meters from 0.001 up to $10000 \mu \mathrm{m}$ of the diverse origins of the fine particles in the planet's atmosphere. From WHO, 2005. Air Quality Guidelines, Global Update 2005. Particulate matter, ozone, nitrogen dioxide and sulfur dioxide. Original figure was kindly provided by Professor Pierre Camps, Montpellier, France.

indicate that presence of magnetic particles occurring in ALL the specimens under question.

\section{Conclusion}

Our study of the magnetic properties such as magnetic susceptibility ( $\mathrm{\chi}$ ), Curie point determination as well as hysteresis loops experiments to determine magnetic grain sizes is in reality constraints to assess the production of traffic-related airborne particulate matter (PM) in the City and County of Honolulu, Hawaii as well as the content of magnetic particles both in cigarettes and burnt ashes. Magnetic susceptibility ranges are from 0.4 (i.e. brake pads) to $768\left(10^{-6} \mathrm{~m}^{3} / \mathrm{kg}\right)$, (see Table 1).

The first magnetic results obtained are the Curie point determinations that clearly indicate that the brake pads of two different vehicles i.e. the Toyota Tacoma 2015 as well as the Toyota Truck 1987 display similar magnetic mineral phases with Curie temperatures between $220^{\circ} \mathrm{C}-596^{\circ} \mathrm{C}$ for both vehicles and a second set of temperatures at approximately $480^{\circ} \mathrm{C}$ and also a definite temperature of $575^{\circ} \mathrm{C}$ to $598^{\circ} \mathrm{C}$. The fine particles of fuel analyzed corresponding to octanes 87 and 92 showed a certain degree of reversibility displaying Curie temperatures of $220^{\circ} \mathrm{C}, 410^{\circ} \mathrm{C}$ and $585^{\circ} \mathrm{C}$ (i.e. ' 99 Sebring Octane 87). The results of the Japanese and Marlboro cigarettes yielded Curie point temperatures from $328^{\circ} \mathrm{C}, 531^{\circ} \mathrm{C}$ and $675^{\circ} \mathrm{C}$ and the burnt ashes indicated temperatures of $\sim 531^{\circ} \mathrm{C}$, 
$572^{\circ} \mathrm{C}$ and $602^{\circ} \mathrm{C}$ (see Table 1 ).

The results of the induced magnetization experiments such as the magnetic hysteresis loops are shown in Figure 2. The most salient features of such determinations are the very small and narrow coercivities of the loops or the so called "wasp-waisted loops" diagrams (Tauxe et al., 1996) that indicate such geometries are generated from populations of Single Domain (SD) and super paramagnetic (SP) grains; these cases are represented by the octane 87 gasoline small particles and the rear and front brake pad particles of the vehicles analyzed. Six of the hysteresis loop diagrams correspond to the Toyota SUV octane 87, Toyota Echo octane 92 and the tobacco and ashes of the Japanese and Marlboro cigarettes depicted in Figure 2. These six loop diagrams in addition show a ferro-ferri-magnetic contribution (i.e. the Ulvospinel-Magnetite magnetic minerals solid solution). They are also characterized by paramagnetic contributions to the hysteresis curves.

The final conclusion about this research note is to point out that vehicles, cigarettes and their smoked ashes have produced very fine magnetic particles that no matter what their sizes are they potentially will cause illnesses that can severely harm the human body (i.e. brain, lungs, heart, liver, see Figure 5 and Figure 6) in the city and county of Honolulu, Oahu, Hawaii, USA.

\section{Acknowledgements}

SOEST-Hawaii Institute of Geophysics and Planetology (HIGP) and the National Science Foundation Grants EAR-Geophysics 1719733 and NSF-IF Grant number 0710571 provided financial support for this study to E. Herrero-Bervera. We also thank the reviews of two anonymous referees of our work. This is SOEST contribution \#10934 and HIGP contribution \#2412.

\section{Conflicts of Interest}

The authors declare no conflicts of interest regarding the publication of this paper.

\section{References}

Curtis, L., Rea, W., Smith-Willis, P., Fenyves, E., \& Pan, Y. (2006). Adverse Effects of Outdoor Air Pollutants. Environment International, 32, 815-830. https://doi.org/10.1016/j.envint.2006.03.012

Day, R., Fuller, M., \& Schmidt, V. A. (1977). Hysteresis Properties of Titanomagnetites: Grain Size and Composition Dependence. Physics of the Earth and Planetary Interiors, 13, 260-267. https://doi.org/10.1016/0031-9201(77)90108-X

Dunlop, D. J. (2002). Theory and Application of the Day Plot (Mrs/Ms versus Hcr/Hc) 2. Application to Data for Rocks, Sediments and Soils. Journal of Geophysical Research, 107, EPM5-1-EPM5-15. https://doi.org/10.1029/2001JB000487

Dunlop, D. J., \& Özdemir, O. (1997). Rock Magnetism: Fundamentals and Frontiers (573 p.). New York: Cambridge University. https://doi.org/10.1017/CBO9780511612794

Herrero-Bervera, E., \& Valet, J. P. (2009). Testing Determinations of Absolute Paleointensity from the 1955 and 1960 Hawaiian Flows. Earth and Planetary Science Letters, 287, 420-433. https://doi.org/10.1016/j.epsl.2009.08.035 
Hrouda, F. (1994). A Technique for the Measurement of Thermal Changes of Magnetic Susceptibility of Weakly Magnetic Rocks by the CS-2 Apparatus and KLY-2 Kappabridge. Geophysical Journal International, 118, 604-612. https://doi.org/10.1111/j.1365-246X.1994.tb03987.x

Hrouda, F., Jelinek, V., \& Zapletal, K. (1997). Refined Technique for Susceptibility Resolution into Ferromagnetic and Paramagnetic Components Based on Susceptibility Temperature Variation Measurements. Geophysical Journal International, 129, 715-719. https://doi.org/10.1111/j.1365-246X.1997.tb04506.x

Jordanova, N., Jordanova, D., Henry, B., Le Goff, M., Dimov, D., \& Tsacheva, T. (2006). Magnetism of Cigarette Ashes. Journal of Magnetism and Magnetic Materials, 301, 50-66. https://doi.org/10.1016/j.jmmm.2005.06.008

Plascencia-Villa, G., Ponce, A., Collinwood, J. F., Arellano-Jimenez, M., Zhu, X., Rogers, J. T., Betancourt, I., Jose-Yacaman, M., \& Perry, G. (2016). High-Resolution Analytical Imaging and Electron Holography of Magnetite Particles in Amyloid Cores of Alzheimer's Disease. Scientific Reports, 6, Article No. 24873.

https://doi.org/10.1038/srep24873

Sagnotti, L., \& Winkler, A. (2012). On the Magnetic Characterization and Quantification of the Superparamagnetic Fraction of Traffic-Related Urban Airborne PM in Rome, Italy. Atmospheric Environment, 59, 131-140.

https://doi.org/10.1016/j.atmosenv.2012.04.058

Tauxe, L., Mullender, T. A. T., \& Pick, T. (1996). Potbellies, Wasp-Waists, and Superparamagnetism in Magnetic Hysteresis. Journal of Geophysical Research, 101, 571-583. https://doi.org/10.1029/95JB03041

Thompson, R., \& Oldfield, F. (1986). Environmental Magnetism. London: Allen \& Unwin Springer. https://doi.org/10.1007/978-94-011-8036-8

WHO (2006). Air Quality Guidelines for Particulate Matter, Ozone, Nitrogen Dioxide and Sulfur Dioxide. In Global Update 2005. Summary of Risk Assessment (30 p.). Geneva: World Health Organization. https://www.who.int/phe/air/aqg2006execsum.pdf 